\title{
Adolescent sex differences in cortico-subcortical functional connectivity during response inhibition
}

\author{
Yu Sun Chung ${ }^{1} \cdot$ Vince Calhoun $^{2,3} \cdot$ Michael C. Stevens ${ }^{1,4}$ \\ Published online: 20 May 2019 \\ (C) The Psychonomic Society, Inc. 2019
}

\begin{abstract}
Numerous lines of evidence have shown that cognitive processes engaged during response inhibition tasks are associated with structure and functional integration of regions within fronto-parietal networks. However, while prior studies have started to characterize how intrinsic connectivity during resting state differs between boys and girls, comparatively less is known about how functional connectivity differs between males and females when brain function is exogenously driven by the processing demands of typical Go/No-Go tasks that assess both response inhibition and error processing. The purpose of this study was to characterize adolescent sex differences and possible changes in sexually dimorphic regional functional connectivity across adolescent development in both cortical and subcortical brain connectivity elicited during a visual Go/No-Go task. A total of 130 healthy adolescents (ages 12-25 years) performed a Go/No-Go task during functional magnetic resonance imaging. High model-order group independent component analysis was used to characterize whole-brain network functional connectivity during response inhibition and then a univariate technique used to evaluate differences related to sex and age. As predicted and similar to previously described findings from non-task-driven resting state connectivity studies, functional connectivity sex differences were observed in several subcortical regions, including the amygdala, caudate, thalamus, and cortical regions, including inferior frontal gyrus engaged most strongly during successful response inhibition and/or error processing. Importantly, adolescent boys and girls exhibited different normative profiles of age-related changes in several default mode networks of regions and anterior cingulate cortex. These results suggest that cortical-subcortical functional networks supporting response inhibition operate differently between sexes during adolescence.
\end{abstract}

Keywords Response inhibition $\cdot$ Adolescence $\cdot$ Sex difference $\cdot$ Functional network connectivity

\section{Introduction}

In the past two decades, there has been a resurgence of interest in describing sex differences to understand how male and female brains function differently (Grabowska, 2017; Gur \& Gur, 2017) in ways that influence cognition and behavior (Theresa, Mary-Lou Pardue, \& Pardue, 2001). A particularly important aspect of cognition is inhibitory control or response

Electronic supplementary material The online version of this article (https://doi.org/10.3758/s13415-019-00718-y) contains supplementary material, which is available to authorized users.

Michael C. Stevens

michael.stevens@hhchealth.org

Yu Sun Chung

Yusun.Chung@hhchealth.org

1 Olin Neuropsychiatry Research Center, 200 Retreat Avenue, Whitehall Building- Institute of Living, Hartford, CT 06106, USA inhibition - defined as the ability to deliberately suppress inappropriate responses towards goal-directed behavior. Normal development of response inhibition is required for successful self-regulation that typically undergoes developmental changes throughout childhood and adolescence in ways that influence many aspects of functioning (Buckley, Cohen, Kramer, McAuley, \& Mullen, 2014). Impaired response inhibition is considered to be a core deficit implicated in impulsivity-
2 The Mind Research Network, Albuquerque, NM, USA

3 Department of Electrical and Computer Engineering, University of New Mexico, Albuquerque, NM, USA

4 Department of Psychiatry, Yale University School of Medicine, 200 Retreat Avenue, Whitehall Building- Institute of Living, Hartford, CT 06106, USA 
related disorders, such as substance dependence. Moreover, this cognitive impairment might underlie large sex differences in clinical presentations and prevalence of such impulsivityrelated disorders that emerge in adolescence (Cotto et al., 2010; Fox \& Sinha, 2009; Kuhn, 2015). It is crucial to understand neural mechanisms underlying adolescent development of response inhibition in a sex-specific way. However, the majority of previous neuroimaging studies of response inhibition do not include a sex as an independent variable (Zhang, Geng, \& Lee, 2017). We currently know little about neural mechanisms that may lead to adolescent sex differences in impulsivity-related disorders characterized by inefficient or failure of response inhibition.

There is an increasing perception that response inhibition is subserved by a large-scale distributed system that includes both bilateral cortical and subcortical regions, including inferior frontal cortex, inferior parietal lobule, pallidum, putamen, and caudate (Zhang et al., 2017). In addition, many response inhibition tasks with challenging and cognitively complex instructions engage other prefrontal-based neural systems to mediate attentional/working memory demands or to process errors in performance (reviewed in Criaud \& Boulinguez, 2013; Hester, Fassbender, \& Garavan, 2004; Sharp et al., 2010). An important aspect of inhibitory control lies not simply in how the brain engages to withhold responses, but how the brain processes and adapts to mistakes. Both error processing and successful response inhibition are crucial elements of Go/No-Go task and Stop-signal task performances (Corbetta \& Shulman, 2002; Hampshire, Chamberlain, Monti, Duncan, \& Owen, 2010; Li, Huang, Constable, \& Sinha, 2006b). For example, withholding a response to "No-Go" stimuli, namely "correct rejects," measures successful response inhibition ability. Reaction times on trials after performance errors are usually longer than reaction times on trials following correct responses - a process referred to as post-error slowing. Both the number of errors and this post-error slowing are all regarded as behavioral indices of error monitoring typically measured in a Go/No-Go task paradigm (Danielmeier \& Ullsperger, 2011; Rabbitt, 1966). Thus, a thorough examination of response inhibition-related cognitive control should consider both successful and unsuccessful demands to withhold motor responses, focusing both on cingulo-opercular networks robustly engaged by errors (Dosenbach et al., 2007; Dosenbach et al., 2006), as well as frontoparietal systems and premotor-cortical-subcortical systems engaged to withhold motor responses.

Although little is known about adolescent sex differences in response inhibition, the most consistent findings from neuroimaging studies of how specific brain systems differ between sexes are that subcortical regions, such as basal gangliaseem to be most likely to show sexual dimorphism in their grey matter structure or white matter connectivity (Giedd, Raznahan, Mills, \& Lenroot, 2012; Ruigrok et al., 2014; Sacher,
Neumann, Okon-Singer, Gotowiec, \& Villringer, 2013). Sex differences in neurocognition appear to exist between adolescence and young adulthood when there is reorganization of cortical-subcortical network of regions (Marek, Hwang, Foran, Hallquist, \& Luna, 2015; Sisk, 2017). For example, when a large sample of participants performed the Penn computerized neurocognitive battery that measured a broad range of cognitive functions, boys outperformed girls on motor and spatial cognitive tasks (Satterthwaite et al., 2015). On the other hand, girls were faster in tasks of emotion identification and nonverbal reasoning. The patterns of cognition were related to masculinity or femininity of their pattern of resting-state functional connectivity (Satterthwaite et al., 2015). Several adolescent brain developmental models (Casey, Jones, \& Hare, 2008; De Bellis et al., 2001; Lenroot \& Giedd, 2010) argue that there are sex differences in the timing of cortical-subcortical maturation. According to those models, females show earlier maturation peak of the frontal regions compared with boys (Giedd et al., 1999; Lenroot \& Giedd, 2010). Both boys and girls show relatively protracted development of the frontal regions than subcortical regions (Casey et al., 2008; De Bellis et al., 2001; Lenroot \& Giedd, 2010). It is possible that brain structures supporting response inhibition may show different adolescent developmental trajectories between sexes. In this context, it is crucial to understand sex-dependent inhibitory control especially in adolescence, because females and males show different levels of neuropsychiatric disorders, such as impulsivity behavior and addiction, characterized by dysregulated inhibitory control (Cotto et al., 2010; Fillmore \& Weafer, 2004; Li, Huang, Constable, \& Sinha, 2006a; Petry, Kirby, \& Kranzler, 2002). For example, males appear to be more susceptible to impairment in inhibitory control and more often to be reported with impulsivity-related problems compared with females (Fillmore \& Weafer, 2004; Petry et al., 2002). Several studies have shown that during stop signal inhibition, males tend to activate many cortical regions and subcortical regions, such as globus pallidus and thalamus more greatly compared with women. On the other hand, women tend to more greatly engage specific cortical regions important to performance monitoring, such as cingulate cortical activation during a stop-signal task (Li et al., 2006a; Li et al., 2008; Li et al., 2009; Mansouri, Fehring, Gaillard, Jaberzadeh, \& Parkington, 2016).

Very few studies have sought to describe sex-dependent patterns of how sexually dimorphic subcortical structures are functionally connected with diverse cortical brain regions. What we know about sex differences in distributed brain network connectivity so far comes mostly from studies using task-free "resting state" fMRI, which can differ from network interactions during task performances in characteristic and important ways (Cole, Bassett, Power, Braver, \& Petersen, 2014; Geerligs, Rubinov, Cam, \& Henson, 2015; Krienen, Yeo, \& Buckner, 2014; Roth, Johnson, Tokoglu, Murphy, \& Constable, 2014). This experimental approach quantifies 
network connectivity in the absence of cognitive task demands to drive neural network activity. In line with previous studies indicating sexually dimorphic brain structure and functional activity studies suggesting sex differences, several resting-state connectivity studies suggest that there are sex differences in terms of how well several subcortical regions coordinate their activation over time with other frontal regions through their afferent and efferent connections (Alarcon, Cservenka, Rudolph, Fair, \& Nagel, 2015; Sacher et al., 2013; Zuo et al., 2010). For example, large-sample studies of resting state connectivity point to connectivity with basal ganglia being stronger in females (Allen et al., 2011; Jung et al., 2015). In particular, a relevant resting-state network to sex differences in the brain is the default mode network (DMN). The DMN is a system whose activity levels tend to be high when task demands are low. Features of slow bloodoxygenation-level dependent (BOLD) fluctuations within the DMN have been linked to multiple brain processes, as evidenced by modulation of the activity of the DMN depending on cognitive loads (Esposito et al., 2006) and the connectivity between DMN and other task-positive networks (i.e., a collection of regions commonly recruited in cognitive tasks) (Hampson, Driesen, Roth, Gore, \& Constable, 2010). Females show stronger intra-DMN connectivity compared with males (Mak et al., 2017). Also, there is some evidence for females' greater resting-state functional connectivity within the DMN, between the DMN and prefrontal regions, and between subcortical and frontal lobe regions compared with males (Bluhm et al., 2008; Hjelmervik, Hausmann, Osnes, Westerhausen, \& Specht, 2014; Tian, Wang, Yan, \& He, 2011). But these studies tell us little about whether or not network integration differs by sex when such DMN connections are called upon to support different types of active cognitive processing. This is important because how functional connectivity operates during certain tasks might be a proxy of sex differences in prior neurocognitive studies of executive function, attention, verbal memory, or emotion (Collaer \& Hines, 1995; Hamson, Roes, \& Galea, 2016; Sommer, Aleman, Bouma, \& Kahn, 2004; Stevens \& Hamann, 2012).

Only a few functional connectivity studies in adolescents associated with response inhibition have been published. Converging findings across these functional connectivity studies are that there is increased functional connectivity among some prefrontal cortex regions (e.g., dorsolateral prefrontal cortex-anterior cingulate cortex coupling) and greater strength between striatum and frontal regions with age during successful inhibitory control (Keulers, Goulas, Jolles, \& Stiers, 2012; Spielberg et al., 2015a; Spielberg, Miller, Heller, \& Banich, 2015b; Stevens, Kiehl, Pearlson, \& Calhoun, 2007; Vink et al., 2014). None of these functional connectivity studies included sex as an independent variable. As such, it is not known whether adolescent girls and boys show similar or different functional connectivity patterns engaged in response inhibition-related cognitive processing. To fill these gaps in the scientific literature, this study asked whether there would be sex differences in regional functional connectivity engaged during performance of a response inhibition task (i.e., Go/No-Go task) in a large sample of healthy adolescents and young adults. Although we were interested in connections among all major brain regions and used a statistical framework appropriate for inferences across the brain, we were particularly interested in subcortical regions with known sexual dimorphism. Even such brain regions like the amygdala or hippocampus could exert direct or indirect effects on the neuronal basis of Go/No-Go-related information processing, despite not being functionally specialized for response inhibition or error processing due to their interconnections with regions that were commonly engaged for those cognitive operations. Accordingly, we hypothesized that adolescent sex differences would be observed in any type of subcorticalcortical network connectivity. In particular, we anticipated that we would be most likely to observe these effects in the amygdala - known to be the most sexual dimorphic region consistently found across prior studies. We predicted that amygdala functional connectivity would be greater in girls consistent with earlier cortical and subcortical maturation peaks in girls (Lenroot \& Giedd, 2010; Lenroot et al., 2007). If so, this would suggest that the effect of amygdala network connectivity maturation extends beyond the conventionally recognized role of this structure in emotional and salience processing into a more domain-general role. We also closely examined DMN regions to determine if similar sexually dimorphic connectivity profiles existed when these regions dynamically changed their levels of activation during response inhibition demands in ways consistent with connectivity profiles previously observed during resting state. Finally, we expected that any functional connectivity sex differences we might find also would differ with increasing age, because numerous prior studies have found network connectivity reorganization from childhood/adolescence to adulthood (Faghiri, Stephen, Wang, Wilson, \& Calhoun, 2018; Luna \& Sweeney, 2004; Marek et al., 2015; Rubia et al., 2006). We expected that girls would show greater functional connectivity changes with increasing age both in cortical and subcortical regions, given the expectation of generally earlier cortical brain system maturation in females (Giedd et al., 1999; Lenroot \& Giedd, 2010).

\section{Methods}

\section{Participants}

The sample included 130 right-handed, healthy adolescents, collected as part of a study supported by the National Institute of Mental Health (R01MH081969). By design, the sample was 
evenly balanced for sex and age across $12-25$ years (66 boys, mean age: $18.39 \pm 3.6$ years; 64 girls, mean age: $18.37 \pm 3.8$ years). No participants had a history of formal learning disability, significant medical conditions, or current mental health disorders as confirmed by the Schedule for Affective Disorders and Schizophrenia for School-Age Children-Present and Lifetime Version (Kaufman et al., 1997) conducted using standard semistructured interview procedures. The Adolescent Alcohol and Drug Involvement Scale (AADIS) (Mayer \& Filstead, 1979; Moberg \& Hahn, 1991) and Fagerstrom Test for Nicotine Dependence (Heatherton, Kozlowski, Frecker, \& Fagerstrom, 1991) confirmed minimal substance use for both boys and girls, which did not differ by sex. Boys $(n=66$, mean: $0.06, \mathrm{SD} \pm 0.39)$ and girls $(n=64$, mean: $0.05, \mathrm{SD}: \pm 0.37) \mathrm{did}$ not differ for nicotine dependence as assessed by Fagerstrom test $[t(127)=0.21, p=0.82]$. Also, boys $(n=66$, mean: 14.51 , SD: \pm 13.47$)$ and girls $(n=64$, mean: 12.18, SD: \pm 12.40$)$ did not differ for AADIS scores $[t(126)=1.01, p=0.31]$. All participants provided written, informed consent in protocols approved by Hartford Hospital's Institutional Review Board. For legal minors, parents provided written permission, and minors provided written assent.

\section{Go/No-Go task}

The fMRI Go/No-Go task was performed in a scanner where frequent ' $X$ ' $(p=0.85)$ and less frequent ' $K$ ' stimuli were presented at a $3 \times 5$ visual degrees for $50 \mathrm{msec}$ each with $1,000 \mathrm{msec}$ of minimum interstimulus interval. Intervals between $K$ stimuli were in the range 10-15 seconds. Participants were asked to make a button press with their right index finger to rapidly presented visual ' $X$ ' (Go) stimuli as soon as possible, while withholding a response to pseudo-randomly interspersed ' $K$ ' (No-Go) stimuli. During a practice trial, speed was emphasized over accuracy to ensure engagement of a prepotent response tendency. With these instructions, participants typically make roughly equivalent numbers of errors and correctly inhibited responses to No-Go stimuli, providing an opportunity to evaluate both aspects of task performance and task-elicited brain activity. E-Prime software was used to closely control stimuli presentation timing. The stimulus sequences were projected to the participant via a screen visible to participants in the MRI by rear-facing mirror attached to the head coil. Before beginning the task, all participants were asked to perform a practice trial to endure that they were familiar with task instructions. A commercially available magnetic resonance imaging (MRI)-compatible fiber-optic response device (Current Designs, Inc.) was used to acquire behavioral responses. Stimulus events and behavioral responses were recorded and monitored online using a separate computer. Correct hits and incorrect response errors were defined as a button press occurring within $1,000 \mathrm{msec}$ of an ' $X$ ' or ' $K$ ' trial, respectively.

\section{Behavioral Performance Data Analysis}

The effects of sex and age by sex effects on the dependent variables were analyzed using multivariate analysis of variance (MANOVA). Post hoc tests to assess linear effects of age on behavioral performance variables were investigated using two-tailed Pearson correlation analyses.

\section{Imaging Parameters and Processing}

MRI data were collected using a Siemens Allegra 3T system located at the Olin Neuropsychiatry Research Center. Localizer images were acquired for use in prescribing the functional image volumes. The echo planar image (EPI) gradient-echo pulse sequence (TR/TE $1,500 / 27 \mathrm{~ms}$, flip angle $60^{\circ}$, FOV $24 \times 24 \mathrm{~cm}, 64 \times 64$ matrix, $3.4 \times 3.4 \mathrm{~mm}$ in plane resolution, 4-mm effective slice thickness, 30 slices) effectively covered the entire brain $(150 \mathrm{~mm})$ in 1.5 seconds. Head motion was restricted using a custom built cushion inside the head coil. The two task runs each consisted of 294 time points, including a 9 -second rest session at the beginning that was collected to allow for T1 effects to stabilize. These first six images were not included in any subsequent analyses.

Brain structure images were prepared for analysis by first correcting for the estimated MRI bias-field using SPM12 software (http://www.fil.ion.ucl.ac.uk/spm/software/) followed by noise reduction using FSL SUSAN filtering software (http://www.fmrib.ox.ac.uk/). Functional images were reconstructed offline and each run was separately realigned using FSL MCFLIRT (Jenkinson, Bannister, Brady, \& Smith, 2002). To control for motion-related confounds, we used a 0.5 -mm cutoff threshold for Framewise Displacement (FD) measurements (Power, 2012) to exclude "noisy" data from analysis. This metric quantifies movements of any given frame relative to the previous frame. Although different methods of measuring FD may differ in the amplitude of measurement and are influenced by TR (i.e., repetition time), FD > $0.5 \mathrm{~mm}$ has been considered to be a stringent threshold (Power, 2012; Power et al., 2015). No subjects were excluded due to this cutoff threshold in current study. Each fMRI timeseries was realigned to the mid-series volume (Jenkinson et al. , 2002), corrected for slice-timing acquisition differences (Jenkinson, Beckmann, Behrens, Woolrich, \& Smith, 2012) and spatial distortions due to inhomogeneity removed using field map-based unwarping (Jenkinson, 2003; Jezzard \& Balaban, 1995). Signal spikes were removed using AFNI 3dDespike (https://afni.nimh.nih.gov/afni/doc/help/ $3 \mathrm{dDespike.html)} \mathrm{and} \mathrm{volumes} \mathrm{were} \mathrm{automatically} \mathrm{reoriented}$ to stereotactic space using 3-parameter rigid body realignment. An example fMRI volume was co-registered to the MPRAGE high-resolution brain structure scans using SPM12 software (http://www.fil.ion.ucl.ac.uk/spm/software), and then spatial normalization parameters mapping the $\mathrm{T} 1$ to 
MNI atlas space were applied to each fMRI volume. Each image of the resulting time-series was spatially smoothed with a 6 mm FWHM Gaussian kernel.

\section{Independent Component Analysis (ICA) Estimation of Functional Connectivity}

Group independent component analysis (ICA) (Calhoun \& Adali, 2012; Calhoun, Adali, Pearlson, \& Pekar, 2001) was used to estimate and quantify each participant's functional connectivity. ICA is a data-driven multivariate analysis method that identifies distinct group of brain regions showing the same temporal pattern of hemodynamic signal change. This ICA approach enables to use a statistical framework optimized for the analysis of large datasets. As presented in Figure 1, the ICA approach uses a hierarchical approach using multivariate models. With this statistical framework, we intended to investigate the effects of age and sex on different aspects of functional connectivity throughout cortical and subcortical structures. ICA was implemented using Group ICA of FMRI Toolbox (GIFT v.4.0b) in Matlab (http://mialab.mrn.org/ software/gift). In addition to typical preprocessing procedures described above, the data were intensity-normalized to improve the accuracy and test-retest reliability of ICA output (Allen et al. , 2011). Spatial ICA applied to fMRI data identifies temporarily coherent networks by estimating maximally independent spatial sources, referred to as spatial maps. High model order ICA (number of components, $\mathrm{C}=80$ ) was used, because this dimensionality yields components that closely correspond to both anatomical and functional segregations compared to low model order ICA (Allen et al., 2011). Practically, a high-order ICA produces components that typically reflect a single region or small groups of brain regions with very tightly intercorrelated fMRI time courses. Subject-specific fMRI data were reduced through two principal component analysis stages and concatenated at each stage for further reduction. For dimension reduction, we used minimum description length to estimate the number of dimensions (Allen et al., 2011). The Infomax ICA algorithm (Bell \& Sejnowski, 1995) was repeated 20 times in ICASSO (ICASSO Toolbox, 2003; http://www.cis.hut.fi/ projects/ica/icasso/), and best stable run estimates were used for ICA estimation prior to component time courses and spatial maps reconstruction for each participant (Ma et al., 2011). The quality of component clusters was quantified using



Note. $\mathrm{FDR}=$ False Discovery Rate

Fig. 1 Schematic diagram of the ICA approach used in current study. Boxes on the left indicate general steps potentially applicable to a variety of data and analysis types; boxes on the right indicate particular choices made for our data and analysis used in current work. FDR $=$ False Discovery Rate 
the index $I q>0.90$, stability coefficient, which ranges from 0 to 1 and reflects the difference between intra-cluster and extracluster similarity (Himberg, Hyvarinen, \& Esposito, 2004). Among 80 components, $I q$ of the majority of components was greater than 0.90 except 7 components whose $I q$ ranged from 0.56 to 0.88 . Two components having $I q<0.69$ were excluded. $I q$ stability coefficients greater than 0.90 are typically considered to be valid in the field (Himberg et al., 2004). Iq of almost all components except one component (i.e., IC 73) that we chose was greater than 0.90 , which fell into the acceptable range. The $I q$ value for IC 73 was 0.77 , which was on the low side. But the bilateral anterior cingulate cortex (ACC) regions represented in IC 73 were too theoretically important to omit from the main analysis. As such, we included this IC in further analyses. Then, among those 78, only 55 components whose fractional amplitude of low-frequency fluctuation (fALFF) was greater than 2 were included in further analyses. fALFF values $>2$ means that the low frequency power was at least twice the high frequency power, which is a reasonable rule-of-thumb when looking for ICAderived components that are driven by low frequency fluctuations and have little signal noise (Allen et al., 2011). fALFF quantifies the ratio between total power within the low-frequency fluctuations $(0.01-0.1 \mathrm{~Hz})$ and total power of the entire frequency range and has been suggested to be sensitive to detecting regional spontaneous brain activity (Zou et al., 2008). Aggregate spatial maps were estimated as the centrotypes of component clusters to reduce sensitivity to initial algorithm parameters. The resulting single-subject time course and component image were then scaled using raw data units.

To identify which components were engaged by response inhibition demands during task performance, we parameterized the component time courses using a multiple regression. This analysis quantifies the association between a component time course and either correct rejects or false alarm conditions of the fMRI task, as represented using the canonical hemodynamic response model in SPM12. These analyses yielded $R^{2}$ values that represented overall association of each task condition in current design to each component time courses. The mean $\beta$-weights showing the relation of each component to experimental condition were examined using one-sample $t$-tests against zero with rigorous FDR of $p<0.0003(=0.05 / 160$ (80 × 2 task regressors, that is, correct rejects and false alarm). Component loadings that differed significantly from zero indicated an association with that condition. Among 55 components, 19 components were determined to be of interest, because they were both associated with either response inhibition or error processing. Visual inspection confirmed that they depicted BOLD signal change within the brain. These 19 components were included in study hypothesis-testing analyses.

\section{Age and Sex Effect fMRI Connectivity Analysis}

Whole brain functional connectivity across task-engaged components was examined using the MANCOVAN toolbox in GIFT v.4.0b (Allen et al., 2011). Although a popular feature of this toolbox is backwards selection of predictors to optimize the statistical power of final multivariate assessment of the component data, we were interested a priori in a full model assessing effects of age, sex, and their interaction. We relied on univariate models and rigorous corrections for multiple comparisons using False Discovery Rate (FDR) (Genovese, Lazar, \& Nichols, 2002 at $p<0.05$. Two types of analyses were employed, each providing complementary information about connectivity. First, we examined the spatial maps that represented the strength of connectivity within the most prominent regions of a component. Second, we examined the crosscorrelation of component time courses (i.e., between network connectivity or functional network connectivity; FNC) to identify pairs of components that were more or less "connected" with each other during task performances. Component spatial maps were thresholded to focus our analysis on the subset of strong and consistently engaged voxels most representative of each network (masked by $t>$ mean +4 standard deviations across positive voxel values within each spatial map). For FNC (Jafri, Pearlson, Stevens, \& Calhoun, 2008), subject-specific time courses were detrended and despiked using 3dDespike (Ances et al., 2009), then filtered using a fifth-order Butterworth low-pass filter with a highfrequency cutoff of $0.15 \mathrm{~Hz}$, and the mean, linear trend, and two sine/cosine cycles were detrended from the data to control for signal drift. Pairwise correlations were computed between component time courses associated with Go/No-Go task performances. These correlations were transformed to $z$-scores using Fisher's transformation.

Our MANCOVAN model included sex (coded as a dummy variable), age, and the corresponding interaction term for these factors. Variance inflation factors for these were less than 2.1. The Wechsler Abbreviated Scale of Intelligence (WASI; Wechsler, 1999) standardized IQ estimates were regressed from all raw data before model estimation to ensure findings could not be better explained by variations in intellectual ability. For spatial map analyses, our univariate analyses isolated the regional peak of the functional connectivity effect for each component. Finally, to graph each significant sex-related effect identified, we extracted participant connectivity values from a 3-mm spherical region of interest centered at each peak effect using MarsBaR (http://marsbar. sourceforge.net/). Averaging of voxels proximal to the peak sex effect generally results in depiction of more stable, generalized effects that were not unduly influenced by any single voxel. For each significant univariate effects of age and sex, we reported Cohen's $d$ effect size (Cohen, 1988) calculated by using $t$-test values. 


\section{Results}

\section{Comparison of Motion Parameters between Boys and Girls}

We wanted to ensure that non-task related artifacts such as head movements during the scanning did not influence any results of sex comparisons. Mean FD values for boys (mean: $0.16 \pm 0.07)$ and girls (mean: $0.16 \pm 0.05$ ) did not differ $(t(128)=0.14, p=0.88)$. Furthermore, we conducted post hoc correlation analysis using mean FD values across two runs to confirm that motion during the scanning was not related to age. Post hoc Pearson correlation revealed a modest, "trend" level association between FD and age for all participants $(r=-0.16, p=0.06)$, consistent with prior published observations (see Supplemental Figure 1 for scatterplot of this association).

\section{Behavioral Performance}

Table 1 shows participants' characteristics and indices of Go/ No-Go task performance. General intelligence scores, as measured by WASI (Wechsler, 1999) between boys (108.55 \pm 11.64) and girls $(107.50 \pm 12.52)$ did not differ $(t(128)=$ $0.49, p=0.62$ ). Behavioral performance on the Go/No-Go task did not significantly differ between boys and girls. There were no sex differences in the number of correct hits or false alarms. Pearson correlation analyses between age and behavioral performance showed that across all subjects, number of correct rejects and false alarm, and mean reaction times for hit and false alarm were associated with age. Both sexes had similar reaction times to all stimuli, as well as nonsignificant results from the age $\times$ sex interaction term test.

\section{Regional Functional Connectivity Effects}

Table 2 lists the component names as localized using maximum correlation with regions in the Desikan-KillianyTourville brain structure atlas (Klein \& Tourville, 2012) and the strength of association with Go/No-Go task conditions (beta-weights and $p$ values) for all 19 task-engaged components included in the univariate connectivity analysis (see for visual depiction of each component).

The MANCOVAN univariate tests on spatial maps depicting strength of regional connectivity found significant main effects of age and sex, as well as age $\times$ sex interaction effects. Regional connectivity strength differed in boys and girls for both cortical and subcortical components where girls had greater functional connectivity compared with boys in several cortical components during both correct rejects (CR) and false alarms (FA) [isthmus cingulate cortex $(\mathrm{IC13}, x y z=53,14,30)(t(126)=-2.26, p=$ $0.02, d=0.40$ ), and right inferior frontal gyrus (IC53, BA44, $x y z=52,14,30)(t(126)=2.19, p=0.03, d=0.39)$ ] and two subcortical components [thalamus (IC22, $x y z=$ $10,-6,16)(t(126)=2.48, p=0.01, d=0.44$ during both CR and FA, and amygdala (IC 18, $t(126)=2.19, p=0.02$, $d=0.39$ ) during FA only] (Figure 2).

Univariate age effect was observed in bilateral superior parietal lobule component (IC65) and rostral middle frontal gyrus component (IC76) both during CR only. As presented in Figure 3, in the right middle frontal gyrus (IC76), increasing age was associated with greater strength of functional connectivity $(t(126)=2.30, p=0.02, d=0.40)$, whereas in the right superior parietal lobule (IC 65, BA39), age was negatively associated with strength of functional connectivity $(t(126)=$ $-2.67 p=0.008, d=0.47$ ).

Furthermore, univariate age $\times$ sex interaction was observed in left pars triangularis (IC 62, BA44, $x y z=-44,4,26$ ) during both CR and FA and bilateral superior parietal (IC 65, BA31) during CR only (FDR, $p<0.05$ ). Girls showed weaker functional connectivity with increasing age in both IC $62(r=$ $-0.29, p=0.01, d=0.16)$ and IC $65(r=-0.44, p<0.0003$, $n=64, d=0.38$ ), whereas boys exhibited no significant associations in all components (all $p$ values $=n s$ ). When graphing this interaction effect, we noticed there was one potential outlier that might have drawn such interaction effect in IC65 but not in IC 62. Even after removing the outlier, the association between age and the strength of functional connectivity in IC65 was the same $(r=-0.45, p<0.0002, n=63, d=0.40$;

Table 1 Behavioral task performance

Healthy adolescents $(n=130)$

Boys $(n=66)$ Mean (SD) Girls $(n=64)$ Mean (SD) Sex differences $F(p) d f=1,130 \quad$ Sex by age $F(p) d f=13,130$ Age correlation

\begin{tabular}{|c|c|c|c|c|c|}
\hline Number of Hit & $202.39( \pm 9.82)$ & $202.13( \pm 6.73)$ & $0.18(0.66)$ & $0.92(0.06)$ & $0.15(0.08)$ \\
\hline Number of CR & $21.23( \pm 7.21)$ & $20.68( \pm 7.21)$ & $0.87(0.35)$ & $0.16(0.15)$ & $\mathbf{0 . 2 8}(0.001)$ \\
\hline Number for FA & $17.76( \pm 7.21)$ & $18.32( \pm 7.63)$ & $0.87(0.35)$ & $0.16(0.15)$ & $-\mathbf{0 . 2 8}(0.001)$ \\
\hline Mean of Hit RT & $0.37( \pm 0.03)$ & $0.37( \pm 0.03)$ & $0.09(0.75)$ & $0.45(0.11)$ & $-\mathbf{0 . 2 6}(0.002)$ \\
\hline Mean of FA RT & $0.34( \pm 0.03)$ & $0.35( \pm 0.04)$ & $0.24(0.62)$ & $0.45(0.11)$ & $-\mathbf{0 . 3 1}(<0.0001)$ \\
\hline
\end{tabular}

Note . $\mathrm{CR}=$ Correct Reject, FA $=$ False Alarm, RT $=$ Reaction Times, Bold numbers indicate Bonferroni-corrected values $(0.05 / 5)$ 
Table 2 Cortical and subcortical independent components associated with response inhibition

\begin{tabular}{|c|c|c|c|c|}
\hline \multirow[t]{2}{*}{ Independent Component (IC) } & \multicolumn{2}{|c|}{ Beta-weights Mean (SD) } & \multicolumn{2}{|l|}{ One-sample $t$-test $p$} \\
\hline & $\mathrm{CR}$ & FA & $\mathrm{CR}$ & FA \\
\hline \multicolumn{5}{|l|}{ Both Correct Rejects (CR) and False Alarm (FA) } \\
\hline 13. Bilateral Isthmus Cingulate Gyrus & $-1.72(2.15)$ & $-1.15(2.71)$ & $p<0.000000000000002$ & $p<.000004$ \\
\hline 22.Bilateral Thalamus Proper & $1.05(1.79)$ & $0.85(2.24)$ & $p<0.0000000007$ & $p<.00004$ \\
\hline 30. Bilateral Precuneus & $-1.17(1.49)$ & $-1.00(1.78)$ & $p<0.000000000000004$ & $p<.000000003$ \\
\hline 37. Right Rostral Middle Frontal gyrus & $1.47(1.89)$ & $0.59(1.41)$ & $p<0.0000000000000008$ & $p<.000005$ \\
\hline 51 Bilateral Posterior Cingulate & $0.96(1.53)$ & $1.29(2.00)$ & $p<0.00000000005$ & $p<.00000000002$ \\
\hline 53. Right Inferior Frontal Gyrus & $1.01(0.86)$ & $0.57(1.01)$ & $p<0.00000000000000000000000006$ & $p<.000000003$ \\
\hline 62. Left Pars Triangularis & $-0.59(1.10)$ & $-0.96(1.45)$ & $p<0.00000002$ & $p<.000000000007$ \\
\hline 71.Bilateral Insula & $0.96(1.20)$ & $2.00(1.96)$ & $p<0.000000000000001$ & $p<.0000000000000000000007$ \\
\hline 73. Bilateral Anterior Cingulate Cortex & $-1.11(1.76)$ & $-1.06(1.81)$ & $p<0.00000000004$ & $p<.0000000006$ \\
\hline \multicolumn{5}{|l|}{ False-alarm only } \\
\hline 18.Bilateral Amygdala & $0.14(1.65)$ & $0.67(2.07)$ & 0.30 & $p<.0004$ \\
\hline 35.Left Inferior Parietal Lobule & $0.02(1.28)$ & $0.58(1.84)$ & 0.80 & $p<.0004$ \\
\hline 56.Left Inferior Parietal Lobule & $0.32(2.08)$ & $1.18(2.62)$ & 0.08 & $p<.0000008$ \\
\hline 60.Bilateral Rostral Anterior Cingulate & $-0.01(0.84)$ & $0.86(1.18)$ & 0.79 & $p<.00000000000009$ \\
\hline \multicolumn{5}{|l|}{ Correct reject only } \\
\hline 33. Bilateral Putamen & $0.63(0.89)$ & $0.02(0.93)$ & $p<0.0000000000003$ & .74 \\
\hline 42. Bilateral Superior Parietal Lobule & $0.95(1.67)$ & $0.13(1.87)$ & $p<0.000000002$ & .41 \\
\hline 46. Bilateral Superior Parietal Lobule & $-1.17(2.10)$ & $-0.17(2.57)$ & $p<0.000000003$ & .42 \\
\hline 49. Bilateral Superior Frontal Lobule & $-0.55(1.22)$ & $0.50(1.76)$ & $p<.000001$ & .001 \\
\hline 65. Bilateral Superior Parietal Lobule & $-0.49(1.09)$ & $-0.38(1.25)$ & $p<0.0000009$ & $p<.0006$ \\
\hline 76. Bilateral Rostral Middle Frontal Gyrus & $0.49(0.96)$ & $0.42(1.75)$ & $p<0.00000004$ & $p<.007$ \\
\hline
\end{tabular}

The table lists each component. The second two columns list the means and standard deviations of regression coefficients indicating the strength of association between each component's ICA time course and Go/No-go task conditions. The last two columns list the significance levels of the onesample $t$ tests used to determine whether these loadings are statistically different from zero. Among all 80 ICs, 19 components below that surpassed rigorous FDR-corrected cut-off $p$ value of .0003 were included in main analyses.

Figure 4, bottom panel). Figure 4 shows the patterns of age $\times$ sex interaction in two components.

\section{Functional Network Connectivity (FNC)}

The FNC analysis revealed only an effect of sex but no age or age by sex interaction effects. We found medium-tolarge sex effects in FNC among several default mode network of regions, including posterior cingulate cortex and anterior cingulate cortex (ACC) engaged during successful response inhibition and/or when error responses were made (Figure 5). Girls showed greater functional connectivity in most pairwise of correlations among components compared with boys. Correlations between posterior cingulate cortex (IC46, xyz $=-12,-78,30)$ and superior parietal lobule (IC65) during CR only and correlations between superior parietal lobule (IC65) during CR only and inferior parietal lobule (IC56, xyz $=18,-44,46$ ) during FA only revealed strong sex effects with girls showing stronger associations among these time courses than boys $\left(R^{2}=\right.$
$0.10, p=0.0002, d=0.7 ; R^{2}=0.14, p<0.000007, d=$ 0.81 , respectively). Also, correlations between ACC $(\mathrm{IC} 73, x y z=54,18,-4)$ during both CR and FA and inferior parietal lobule (IC56, xyz $=18,-44,46$ ) during FA only showed medium effect size of sex differences, with girls having greater functional connectivity compared with boys $\left(R^{2}=0.08, p=0.0009, d=0.6\right)$. The opposite pattern was observed only in the correlation between precentral gyrus (IC51, xyz $=12,-26,72$ ) during both CR and FA and inferior parietal lobule (IC56) during FA only, with boys showing greater association strength among component time courses than girls $\left(R^{2}=0.10, p<0.0002, d=\right.$ $0.70)$.

\section{Discussion}

The goal of this study was to study adolescent sex differences in task-related functional connectivity for the brain regions engaged during performance of a typical response inhibition 


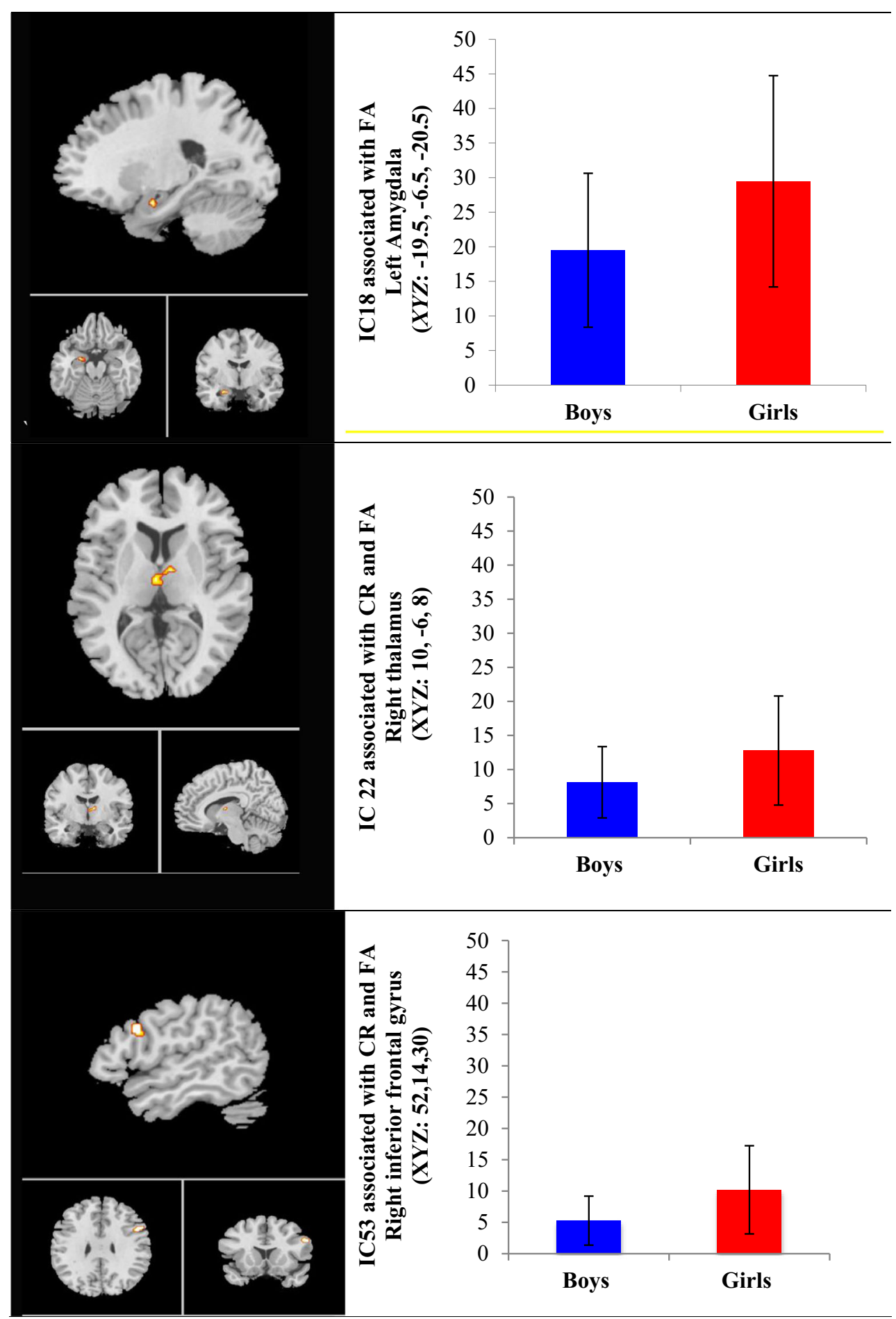

Fig. 2 Sex effects in functional connectivity associated with Go/No-Go Task Performance

task. As expected and consistent with previous meta-analytic studies in adulthood (Criaud \& Boulinguez, 2013; Zhang et al., 2017), we found that task demands to inhibit a prepotent motor response engaged a large number of cortical and subcortical regions commonly engaged during response inhibition (Zhang et al., 2017) or error processing (Neta et al., 2015). As hypothesized, we found that the strength of functional connectivity among brain regions within this functionally engaged system was greater for girls than boys in several subcortical and cortical regions. Also as predicted, adolescent boys and girls exhibited different patterns of agerelated changes in the strength of regional functional connectivity in the right middle frontal gyrus and superior parietal lobule. More importantly, in support of our primary study 


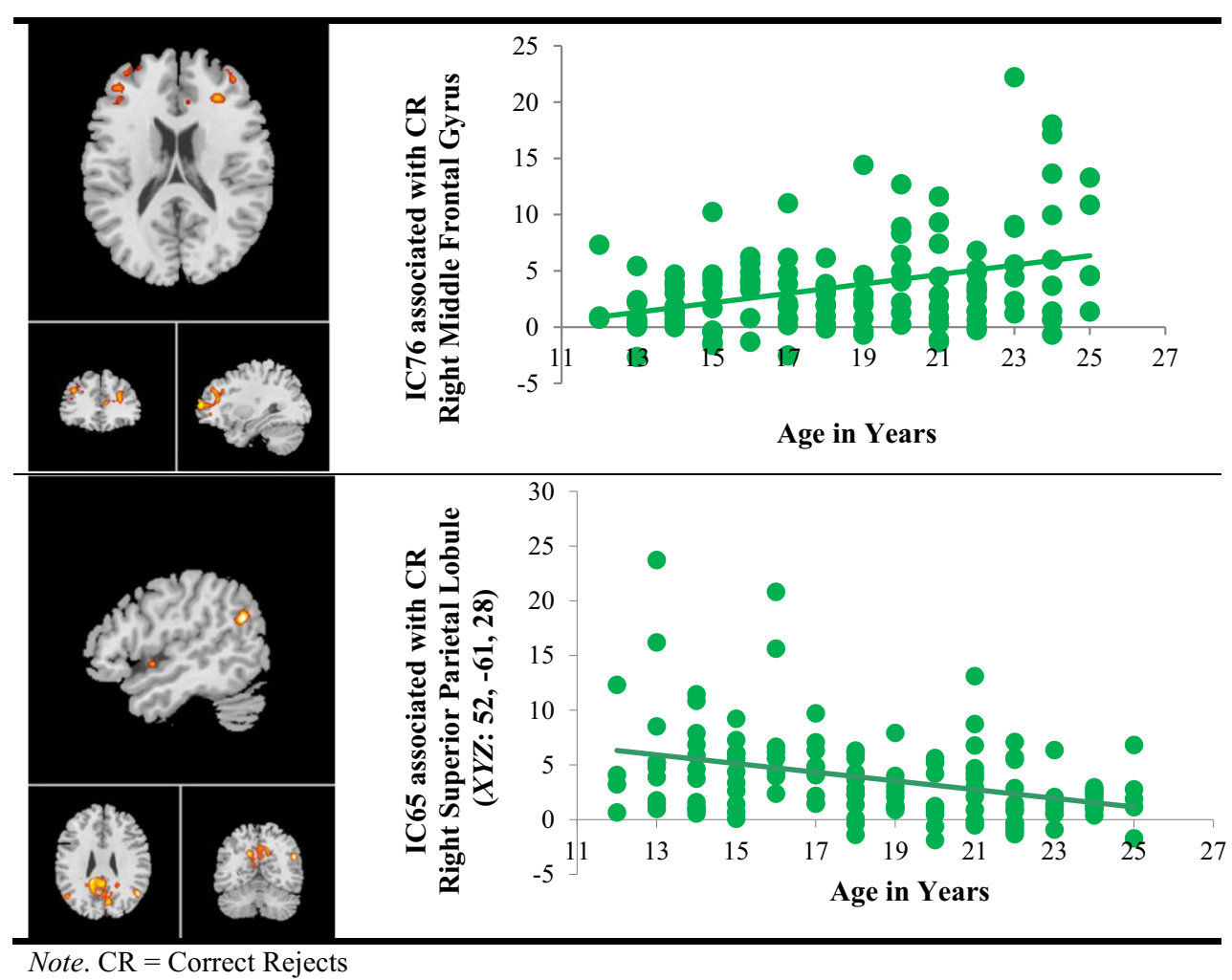

Fig. 3 Age effects in functional connectivity associated with Go/No-Go Task Performance. CR = Correct Rejects

objective, we found medium-to-large sex effects in different types of regional functional connectivity relationships that implicated both subcortical regions and cortical brain regions. There is mounting evidence for sex differences within resting-state functional connectivity data from adolescence to early adulthood (Alaerts, Swinnen, \& Wenderoth, 2016; Rubin et al., 2017; Weis, Hodgetts, \& Hausmann, 2017) and some evidence even in old age (Monroe et al., 2017) but no clear evidence for sex differences between childhood and adolescence (Etchell et al., 2018; Sole-Padulles et al., 2016). To our knowledge, this is the first study to observe adolescent sex differences in functionally integrated cortico-subcortical regional functional connectivity evoked during a Go/No-Go task. Finally, also as predicted and commensurate in size with the medium effect of sex observed for within-region functional connectivity (Cohen's $d$ : 0.39-0.47), our functional network of regional functional connectivity analyses revealed large sex effects (Cohen's $d$ : 0.66-0.85) among different brain regions and between DMN and ACC. In general, girls showed greater cross-network integration during error processing and/or successful response inhibition, whereas boys showed greater functional network connectivity between two specific DMN regions during the same task conditions.

Although we found the associations among these specific network connectivity sex differences engaged during response inhibition and/or error processing, the experimental design prevents us from more directly determining their functional significance. The involvement of ACC suggests that these sex differences have implications for effective top-down control of the ACC to cortical and subcortical regions during error commission, possibly involving either awareness of errors and mobilization of cortically mediated processing resources. This interpretation reflects an extensive literature that notes the connectivity of ACC puts it a key position for a top-down modulation of self-regulation (Devinsky, Morrell, \& Vogt, 1995), as well as a synthesis of intersecting theoretical ideas about what local neuronal processing in different ACC divisions contribute to cognitive control (Bush, Luu, \& Posner, 2000; Etkin, Egner, \& Kalisch, 2011; Mohanty et al., 2007). The most comprehensive theories of ACC function (Botvinick, 2007; Shackman et al., 2011) converge on its key role in conflict detection, performance monitoring, and response-selection (Alexander \& Brown, 2010; Botvinick, Braver, Barch, Carter, \& Cohen, 2001; Braem et al., 2017; Carter et al., 1998; Ridderinkhof, Ullsperger, Crone, \& Nieuwenhuis, 2004). In response to inhibition-related functional network, the ACC is thought to contribute to not just detecting and monitoring errors but also evaluating the degree of the error to form an appropriate form of action to be implemented by the motor system (Weston, 2012). 

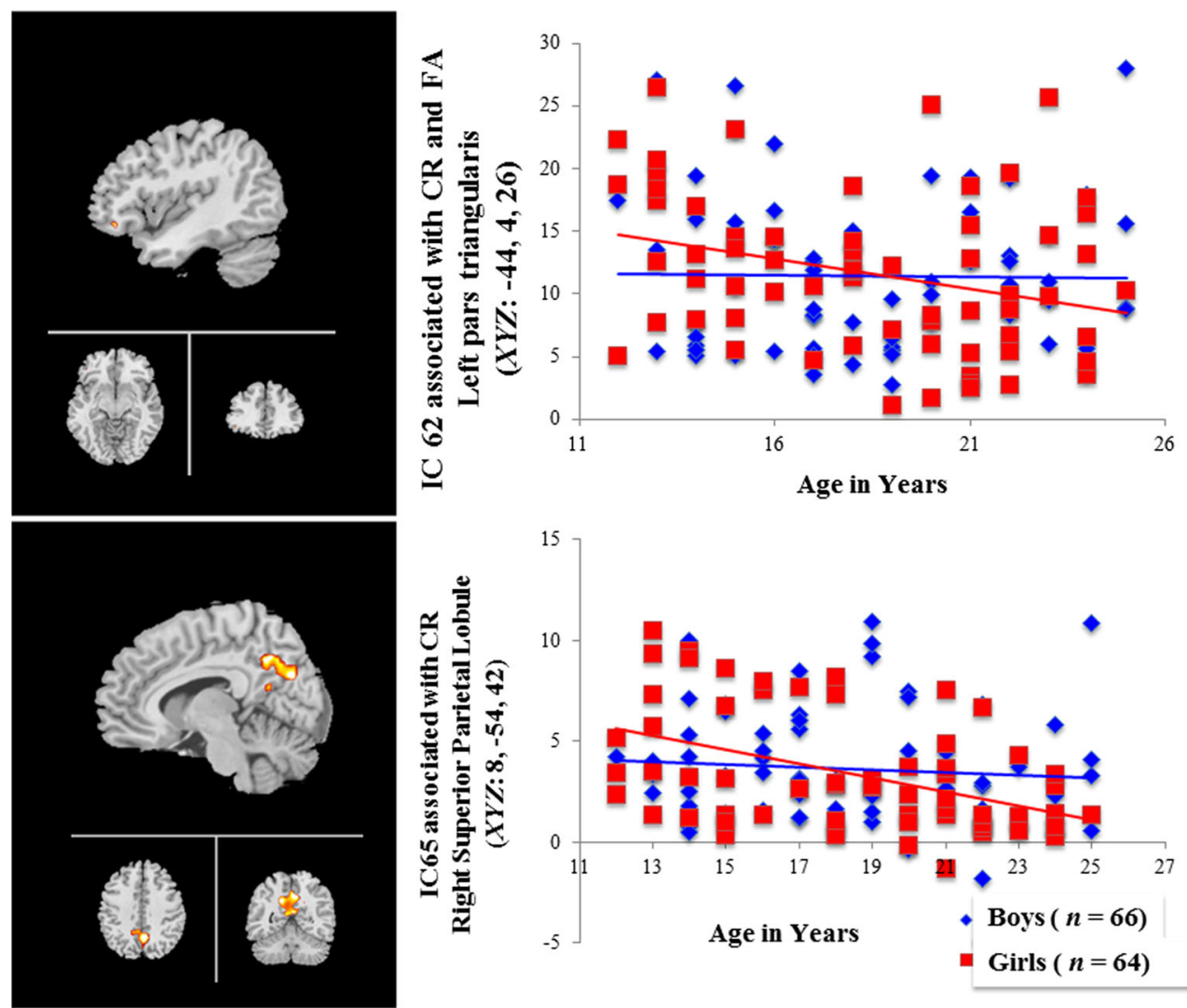

Note. $\mathrm{CR}=$ Correct Rejects, $\mathrm{FA}=$ False Alarm

Fig. 4 Sex-specific age effect in functional connectivity associated with Go/No-Go task performance. $\mathrm{CR}=\mathrm{Correct}$ Rejects, FA = False Alarm

However, it should be noted that these sex differences in brain functional connectivity pattern appeared in the absence of behavioral performances between sexes. This is not without precedent; sex differences in brain activity despite no behavioral differences are observed in several previous fMRI studies in healthy young adults (Chen et al., 2007; Clements et al., 2006; Smith et al., 2014) and middle age (Baxter et al., 2003) across different task domains. Such absence of performance differences often is attributed to the use of different neurocognitive strategies between the sexes, e.g., males and females relying on relatively different types of cognitive processes to achieve the same result on a task. This is consistent with several theories about sex differences in the brain, emphasizing compensational mechanisms underlying sex differences in adults and developing brain and behavior (Cahill, 2006; De Vries, 2004; de Vries \& Sodersten, 2009; Grabowska, 2017; Gur \& Gur, 2017; McCarthy, 2016). In this framework, one can speculate that girls may have used topdown control supported by the ACC in cooperation with parietal lobe regions, whereas boys may have relied relatively more upon bottom-up attentional processing supported by several DMN regions including posterior cingulate cortex and inferior parietal cortex. Alternatively, several studies have focused on task-positive and default mode anti-correlation (Bluhm et al., 2011; Fox et al., 2005; Raichle, 2015). As such, these results could imply that girls had less anticorrelation between DMN and the ACC compared with boys during error processing and/or successful response inhibition, possibly indicative of girls' reallocating attentional resources to more task-relevant information toward successful response inhibition, because the DMN is typically associated with inwards direction of attention, such as engagement in self-referential thoughts (Andrews-Hanna, Reidler, Huang, \& Buckner, 2010; Greicius, Krasnow, Reiss, \& Menon, 2003; Long et al., 2008). Whereas further experimentation will be needed that manipulates these cognitive processes directly to test these possibilities, the current results lay a foundation of network connectivity sex differences among ACC and DMN regions during response inhibition and error processing conditions.

The current findings also shed some light on contentious theories about the overarching organization and impact of brain system sex differences, if only in that they fail to support clearly the two recently popularized theories. Theories have contrasted a strictly dimorphic view that the human brain takes one of two forms: a female or male brain versus an intersex view that human the brain is a mosaic of 


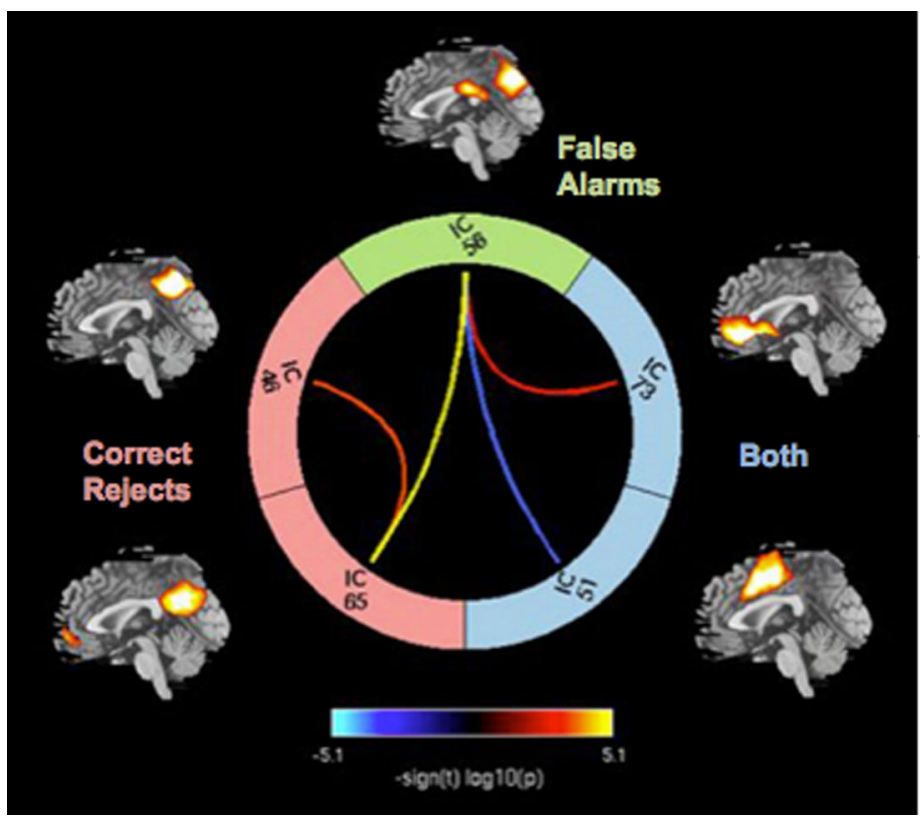

Note. BOTH $=$ both correct rejects and false alarms, $\mathrm{IC}=$ Independent Components, $\mathrm{IC} 46=$ Superior parietal lobule , IC 51= Posterior cingulate cortex, IC $56=$ Inferior parietal cortex, IC $65=$ Superior parietal lobule, IC $73=$ Anterior Cingulate Cortex

Fig. 5 Functional network connectivity of sex effect. Colorful lines represent significance and direction of each pairwise correlation among five components as displayed by $-\operatorname{sign}(t) \log 10(p)$. Hot color lines represent greater functional network connectivity for girls than boys while cool color lines indicate greater functional network connectivity for boys than girls. $\mathrm{BOTH}=$ both correct rejects and false alarms, $\mathrm{IC}=$ Independent Components, IC $46=$ Superior parietal lobule , IC $51=$ Posterior cingulate cortex, IC $56=$ Inferior parietal cortex, IC $65=$ Superior parietal lobule, IC $73=$ Anterior Cingulate Cortex

theories that have proposed compensatory sex-dependent processes that act to reduce rather than create differences between females and males in adulthood.

Another interesting finding to emerge from this study involved sex-specific changes in regional functional connectivity across adolescence and early adulthood. As expected, patterns of age-related brain maturation differed in boys and girls in cortico-subcortical regional functional connectivity, with girls having weaker regional functional connectivity with increasing age. That is, adolescent boys and girls showed different developmental trajectories of cortico-subcortical functional connectivity associated with response inhibition and/or error processing. Although this study cannot directly speak to the exact neural changes that underlie such sex-specific developmental trajectories, we can speculate about potential mechanisms that might influence them using ideas from prevailing theories of adolescent brain development. One potential mechanism might be the reorganization of cortico-subcortical networks over the course of adolescent brain maturation through synaptic pruning and increasing myelination, allowing for more efficient distal neural communication in ways believed to enhance cognitive control (Luna, Marek, Larsen, Tervo-Clemmens, \& Chahal, 2015; Luna, Padmanabhan, \& O'Hearn, 2010; Luna \& Sweeney, 2004). Specifically, according to an integrative model of cognitive control development (Luna et al., 2015), successful 
development of cognitive control is supported by effective large-scale integration of segregated component processes. By the onset of adolescence, the organization, number, and connectivity of the hub architecture of neural connections among regions that support cognitive control are generally adult-like (Hwang, Hallquist, \& Luna, 2013). But a process of increased integration, arguably a key factor leading to efficient cognitive control, such as inhibitory control, may be reflected in increases in the strength of connectivity between prefrontal hub and nonhub regions from childhood to adolescence (Hwang et al., 2013). Such increased integration also may be reflected in a shift in the predominance of local to distributed but stronger strengths of circuit engagement from children to young adults with adolescents having intermediate changes (Cao et al., 2014; Fair et al., 2009; Fair et al., 2007; Supekar, Musen, \& Menon, 2009). In line with these arguments, it is possible to speculate that decreased regional functional connectivity with age in girls may reflect reduced local processing demands that could lower the BOLD responses due to greater synchronization of other brain systems supporting response inhibition over age in early adulthood (Ghuman, Bar, Dobbins, \& Schnyer, 2008). This speculation awaits further testing in future studies.

One thing to consider in a future study is the inclusion of pubertal status information for boys and girls. Puberty is a central event in the reorganization of the cortex, especially the prefrontal cortex based on both animal and human studies (see Juraska \& Willing (2017) for recent review). Many sex differences require hormonal activation during adolescence to manifest (Schulz, Molenda-Figueira, \& Sisk, 2009; Schulz \& Sisk, 2016). More directly, sex steroid hormone surges (i.e., estradiol for girls and testosterone for boys) that occur with the onset of puberty modulate cortico-subcortical functional connectivity (Peper, van den Heuvel, Mandl, Hulshoff Pol, \& van Honk, 2011). There also is empirical evidence that more advanced puberty stage is associated with enhanced functional connectivity of the dorsolateral prefrontal cortex and anterior temporal cortex independent of age in adolescent girls (Klapwijk, 2013). It will be important to learn whether the task-elicited sex differences and changing developmental trajectories by sex described here are causally linked to pubertal onset and hormone-based surges. As such, it is possible that sex differences in brain function are specific to certain pubertal stages that are not necessarily revealed by group average across broad age ranges.

Furthermore, age effects were found only in two components in superior parietal lobule and rostral middle frontal gyrus but no age effect in functional network analysis in current study. This might mean that network-to-network connectivity differences in response inhibition/error-processing context do not mature throughout adolescence. Alternatively, because we only examined participants up to age 25 years, agerelated functional network changes might be detectable if we had studied a broader range of ages and/or later developmental stages of young- or middle-adulthood. We cannot rule out this possibility as prior studies using comparable methodology (Allen et al., 2011) found age-related reductions functional network connectivity when studying participants in a broad range of adulthood ( $N=603$, mean age: $23.4 \pm 9.2)$. However, because that study was of "resting state," definitive conclusions about response inhibition-related network connectivity could not be assumed. In contrast to the dozens of studies of resting state functional connectivity, far fewer studies have examined adolescent age differences in functional connectivity during response inhibition, error processing, or other relevant types of cognitive control tasks (Stevens, 2016). Although the majority of previous studies about response inhibition typically found linear age-related developments from childhood/adolescence to adulthood (Paulsen, Hallquist, Geier, \& Luna, 2015; Rubia, Smith, Taylor, \& Brammer, 2007), it also is possible that a linear model of age effects in current study may not have detected potential age effects in further other components. A longitudinal study design would be ideal to delineate sex-specific developmental trajectories of functional connectivity as a function of pubertal status. Also, to confirm that differences in functional network connectivity are not due to differences in intrinsic network architecture, it is necessary to direct compare resting-state functional connectivity with task-related functional network connectivity using several executive tasks in future study. Finally, this initial report of adolescent sex differences in cortico-subcortical functional connectivity engaged during response inhibition task needs to be replicated in future studies with different cognitive task paradigms to determine if they are context specific or are conserved across different types of cognitively demanding tasks. It is necessary to confirm further whether sex differences exist at a network level when a large-scale of corticosubcortical network of brain regions is called upon during different cognitive task demands.

\section{Conclusions}

The current moderate-sample study of healthy adolescents and young adults revealed strong effects of sex differences in cortico-subcortical functional network connectivity associated with error processing and successful response inhibition. Such findings add to arguments for why we should care about sex differences in adolescent brain. Despite evidence for large sex differences in behavioral dysregulation - arguably due to an inefficient or failure of inhibitory control such as impulsiveness (Cross, Copping, \& Campbell, 2011) - the majority of neuroimaging studies have averaged behavioral and/or neural responses in females and males and boys and girls, with the rationale that sex difference outside of reproductive physiology is small (see Stevens (2016) for recent adolescent functional connectivity review). We argue that both two sexes need to 
be compared directly rather than including either one sex or averaging two sexes' responses. Theories about sex differences in the brain have been of great interest in the past two decades, not simply to characterize neurocognitive differences between sexes, but because those differences could provide a crucial clues that help us understand the sex-linked mechanisms that underlie psychopathology (Rutter, Caspi, \& Moffitt, 2003). In particular, investigations of sex differences in developmental context is required to understand sex-biased several risk factors emerging in adolescence (e.g., sex differences in alcohol use and associated problems) (Schulte, Ramo, \& Brown, 2009).

Acknowledgments This study was supported by the NIMH R01MH081969 and R01MH080956. The authors all thank all participations, the neuroimaging staff, and research staff at the Olin Neuropsychiatry Research Center.

\section{Compliance with ethical standards}

Conflicts of interest The authors declare that the research was conducted in the absence of any commercial or financial relationships that could be construed as a potential conflict of interest.

\section{References}

Alaerts, K., Swinnen, S. P., \& Wenderoth, N. (2016). Sex differences in autism: a resting-state fMRI investigation of functional brain connectivity in males and females. Soc Cogn Affect Neurosci, 11(6), 1002-1016. doi:https://doi.org/10.1093/scan/nsw027

Alarcon, G., Cservenka, A., Rudolph, M. D., Fair, D. A., \& Nagel, B. J. (2015). Developmental sex differences in resting state functional connectivity of amygdala sub-regions. Neuroimage, 115, 235-244. doi:https://doi.org/10.1016/j.neuroimage.2015.04.013

Alexander, W. H., \& Brown, J. W. (2010). Computational models of performance monitoring and cognitive control. Top Cogn Sci, 2(4), 658-677. doi:https://doi.org/10.1111/j.1756-8765.2010.01085.x

Allen, E. A., Erhardt, E. B., Damaraju, E., Gruner, W., Segall, J. M., Silva, R. F., . . . Calhoun, V. D. (2011). A Baseline for the Multivariate Comparison of Resting-State Networks. Front Syst Neurosci, 5. doi:https://doi.org/10.3389/fnsys.2011.00002

Ances, B. M., Liang, C. L., Leontiev, O., Perthen, J. E., Fleisher, A. S., Lansing, A. E., \& Buxton, R. B. (2009). Effects of aging on cerebral blood flow, oxygen metabolism, and blood oxygenation level dependent responses to visual stimulation. Hum Brain Mapp, 30(4), 1120-1132. doi:https://doi.org/10.1002/hbm.20574

Andrews-Hanna, J. R., Reidler, J. S., Huang, C., \& Buckner, R. L. (2010). Evidence for the default network's role in spontaneous cognition. $J$ Neurophysiol, 104(1), 322-335. doi:https://doi.org/10.1152/jn. 00830.2009

Baxter, L. C., Saykin, A. J., Flashman, L. A., Johnson, S. C., Guerin, S. J., Babcock, D. R., \& Wishart, H. A. (2003). Sex differences in semantic language processing: a functional MRI study. Brain Lang, 84(2), 264-272.

Bell, A. J., \& Sejnowski, T. J. (1995). An information-maximization approach to blind separation and blind deconvolution. Neural Comput, 7(6), 1129-1159.

Bluhm, R. L., Clark, C. R., McFarlane, A. C., Moores, K. A., Shaw, M. E., \& Lanius, R. A. (2011). Default network connectivity during a working memory task. Hum Brain Mapp, 32(7), 1029-1035. doi: https://doi.org/10.1002/hbm.21090

Bluhm, R. L., Osuch, E. A., Lanius, R. A., Boksman, K., Neufeld, R. W., Theberge, J., \& Williamson, P. (2008). Default mode network connectivity: effects of age, sex, and analytic approach. Neuroreport, 19(8), 887-891.doi:https://doi.org/10.1097/WNR. 0b013e328300ebbf

Botvinick, M. M. (2007). Conflict monitoring and decision making: reconciling two perspectives on anterior cingulate function. Cogn Affect Behav Neurosci, 7(4), 356-366.

Botvinick, M. M., Braver, T. S., Barch, D. M., Carter, C. S., \& Cohen, J. D. (2001). Conflict monitoring and cognitive control. Psychol Rev, 108(3), 624-652.

Braem, S., King, J. A., Korb, F. M., Krebs, R. M., Notebaert, W., \& Egner, T. (2017). The role of the anterior cingulate cortex in the affective evaluation of conflict. $J$ Cogn Neurosci, 29(1), 137-149. doi:https://doi.org/10.1162/jocn_a_01023

Buckley, J., Cohen, J. D., Kramer, A. F., McAuley, E., \& Mullen, S. P. (2014). Cognitive control in the self-regulation of physical activity and sedentary behavior. Front Hum Neurosci, 8. doi:https://doi.org/ 10.3389/fnhum. 2014.00747

Bush, G., Luu, P., \& Posner, M. I. (2000). Cognitive and emotional influences in anterior cingulate cortex. Trends Cogn Sci, 4(6), 215222.

Cahill, L. (2006). Why sex matters for neuroscience. Nat Rev Neurosci, 7(6), 477-484. doi:https://doi.org/10.1038/nrn1909

Calhoun, V. D., \& Adali, T. (2012). Multisubject independent component analysis of fMRI: a decade of intrinsic networks, default mode, and neurodiagnostic discovery. IEEE Rev Biomed Eng, 5, 60-73. doi: https://doi.org/10.1109/rbme.2012.2211076

Calhoun, V. D., Adali, T., Pearlson, G. D., \& Pekar, J. J. (2001). A method for making group inferences from functional MRI data using independent component analysis. Hum Brain Mapp, 14(3), 140-151.

Cao, M., Wang, J. H., Dai, Z. J., Cao, X. Y., Jiang, L. L., Fan, F. M., . . . He, Y. (2014). Topological organization of the human brain functional connectome across the lifespan. Dev Cogn Neurosci, 7, 76-93. doi:https://doi.org/10.1016/j.den.2013.11.004

Carter, C. S., Braver, T. S., Barch, D. M., Botvinick, M. M., Noll, D., \& Cohen, J. D. (1998). Anterior cingulate cortex, error detection, and the online monitoring of performance. Science, 280(5364), 747-749.

Casey, B. J., Jones, R. M., \& Hare, T. A. (2008). The adolescent brain. Ann N Y Acad Sci, 1124, 111-126. doi:https://doi.org/10.1196/ annals. 1440.010

Chen, C., Xue, G., Dong, Q., Jin, Z., Li, T., Xue, F., . . Guo, Y. (2007). Sex determines the neurofunctional predictors of visual word learning. Neuropsychologia, 45(4), 741-747. doi:https://doi.org/10.1016/ j.neuropsychologia.2006.08.018

Clements, A. M., Rimrodt, S. L., Abel, J. R., Blankner, J. G., Mostofsky, S. H., Pekar, J. J., . . . Cutting, L. E. (2006). Sex differences in cerebral laterality of language and visuospatial processing. Brain Lang, 98(2), 150-158. doi:https://doi.org/10.1016/j.bandl.2006.04. 007

Cohen, J. (1988). Statistical power analysis for the behavioral sciences (2nd ed.). Hillsdale, NJ: Lawrence Earlbaum Associates.

Cole, M. W., Bassett, D. S., Power, J. D., Braver, T. S., \& Petersen, S. E. (2014). Intrinsic and task-evoked network architectures of the human brain. Neuron, 83(1), 238-251. doi:https://doi.org/10.1016/j. neuron.2014.05.014

Collaer, M. L., \& Hines, M. (1995). Human behavioral sex differences: a role for gonadal hormones during early development? Psychol Bull, $118(1), 55-107$.

Corbetta, M., \& Shulman, G. L. (2002). Control of goal-directed and stimulus-driven attention in the brain. Nat Rev Neurosci, 3(3), 201215. doi:https://doi.org/10.1038/nrn755

Cotto, J. H., Davis, E., Dowling, G. J., Elcano, J. C., Staton, A. B., \& Weiss, S. R. (2010). Gender effects on drug use, abuse, and 
dependence: a special analysis of results from the National Survey on Drug Use and Health. Gend Med, 7(5), 402-413. doi:https://doi. org/10.1016/j.genm.2010.09.004

Criaud, M., \& Boulinguez, P. (2013). Have we been asking the right questions when assessing response inhibition in go/no-go tasks with fMRI? A meta-analysis and critical review. Neurosci Biobehav Rev, 37(1), 11-23. doi:https://doi.org/10.1016/j.neubiorev.2012.11.003

Cross, C. P., Copping, L. T., \& Campbell, A. (2011). Sex differences in impulsivity: a meta-analysis. Psychol Bull, 137(1), 97-130. doi: https://doi.org/10.1037/a0021591

Danielmeier, C., \& Ullsperger, M. (2011). Post-error adjustments. Front Psychol, 2, 233. doi:https://doi.org/10.3389/fpsyg.2011.00233

De Bellis, M. D., Keshavan, M. S., Beers, S. R., Hall, J., Frustaci, K., Masalehdan, A., . . . Boring, A. M. (2001). Sex differences in brain maturation during childhood and adolescence. Cereb Cortex, 11(6), 552-557.

De Vries, G. J. (2004). Minireview: Sex differences in adult and developing brains: compensation, compensation, compensation. Endocrinology, 145(3), 1063-1068. doi:https://doi.org/10.1210/en. 2003-1504

de Vries, G. J., \& Sodersten, P. (2009). Sex differences in the brain: the relation between structure and function. Horm Behav, 55(5), 589596. doi:https://doi.org/10.1016/j.yhbeh.2009.03.012

Devinsky, O., Morrell, M. J., \& Vogt, B. A. (1995). Contributions of anterior cingulate cortex to behaviour. Brain, 118 (Pt 1), 279-306.

Dosenbach, N. U., Fair, D. A., Miezin, F. M., Cohen, A. L., Wenger, K. K., Dosenbach, R. A., . . Petersen, S. E. (2007). Distinct brain networks for adaptive and stable task control in humans. Proc Natl Acad Sci U S A, 104(26), 11073-11078.

Dosenbach, N. U., Visscher, K. M., Palmer, E. D., Miezin, F. M., Wenger, K. K., Kang, H. C., . . . Petersen, S. E. (2006). A core system for the implementation of task sets. Neuron, 50(5), 799-812. doi:https://doi. org/10.1016/j.neuron.2006.04.031

Esposito, F., Bertolino, A., Scarabino, T., Latorre, V., Blasi, G., Popolizio, T., . . . Di Salle, F. (2006). Independent component model of the default-mode brain function: Assessing the impact of active thinking. Brain Res Bull, 70(4-6), 263-269. doi:https://doi.org/10.1016/j. brainresbull.2006.06.012

Etchell, A., Adhikari, A., Weinberg, L. S., Choo, A. L., Garnett, E. O., Chow, H. M., \& Chang, S. E. (2018). A systematic literature review of sex differences in childhood language and brain development. Neuropsychologia, 114, 19-31. doi:https://doi.org/10.1016/j. neuropsychologia.2018.04.011

Etkin, A., Egner, T., \& Kalisch, R. (2011). Emotional processing in anterior cingulate and medial prefrontal cortex. Trends Cogn Sci, 15(2), 85-93. doi:https://doi.org/10.1016/j.tics.2010.11.004

Faghiri, A., Stephen, J. M., Wang, Y. P., Wilson, T. W., \& Calhoun, V. D. (2018). Changing brain connectivity dynamics: From early childhood to adulthood. Hum Brain Mapp, 39(3), 1108-1117. doi:https:// doi.org/10.1002/hbm.23896

Fair, D. A., Cohen, A. L., Power, J. D., Dosenbach, N. U., Church, J. A., Miezin, F. M., .. . Petersen, S. E. (2009). Functional brain networks develop from a "local to distributed" organization. PLoS Comput Biol, 5(5), e1000381. doi:https://doi.org/10.1371/journal.pcbi. 1000381

Fair, D. A., Dosenbach, N. U., Church, J. A., Cohen, A. L., Brahmbhatt, S., Miezin, F. M., . . S Schlaggar, B. L. (2007). Development of distinct control networks through segregation and integration. Proc Natl Acad Sci U S A, 104(33), 13507-13512. doi:https://doi.org/10. 1073/pnas.0705843104

Fillmore, M. T., \& Weafer, J. (2004). Alcohol impairment of behavior in men and women. Addiction, 99(10), 1237-1246. doi:https://doi.org/ 10.1111/j.1360-0443.2004.00805.x

Fox, H. C., \& Sinha, R. (2009). Sex differences in drug-related stresssystem changes: implications for treatment in substance-abusing women. Harv Rev Psychiatry, 17(2), 103-119. doi:https://doi.org/ 10.1080/10673220902899680

Fox, M. D., Snyder, A. Z., Vincent, J. L., Corbetta, M., Van Essen, D. C., $\&$ Raichle, M. E. (2005). The human brain is intrinsically organized into dynamic, anticorrelated functional networks. Proc Natl Acad Sci U S A, 102(27), 9673-9678. doi:https://doi.org/10.1073/pnas. 0504136102

Geerligs, L., Rubinov, M., Cam, C., \& Henson, R. N. (2015). State and Trait Components of Functional Connectivity: Individual Differences Vary with Mental State. J Neurosci, 35(41), 1394913961. doi:https://doi.org/10.1523/jneurosci.1324-15.2015

Genovese, C. R., Lazar, N. A., \& Nichols, T. (2002). Thresholding of statistical maps in functional neuroimaging using the false discovery rate. Neuroimage, 15(4), 870-878.

Ghuman, A. S., Bar, M., Dobbins, I. G., \& Schnyer, D. M. (2008). The effects of priming on frontal-temporal communication. Proc Natl Acad Sci U S A, 105(24), 8405-8409. doi:https://doi.org/10.1073/ pnas. 0710674105

Giedd, J. N., Blumenthal, J., Jeffries, N. O., Castellanos, F. X., Liu, H., Zijdenbos, A., . . . Rapoport, J. L. (1999). Brain development during childhood and adolescence: a longitudinal MRI study. Nat Neurosci, 2(10), 861-863. doi:https://doi.org/10.1038/13158

Giedd, J. N., Raznahan, A., Mills, K. L., \& Lenroot, R. K. (2012). Review: magnetic resonance imaging of male/female differences in human adolescent brain anatomy. Biol Sex Differ, 3(1), 19. doi: https://doi.org/10.1186/2042-6410-3-19

Grabowska, A. (2017). Sex on the brain: Are gender-dependent structural and functional differences associated with behavior? JNeurosci Res, 95(1-2), 200-212. doi:https://doi.org/10.1002/jnr.23953

Greicius, M. D., Krasnow, B., Reiss, A. L., \& Menon, V. (2003). Functional connectivity in the resting brain: a network analysis of the default mode hypothesis. Proc Natl Acad Sci U S A, 100(1), 253258. doi:https://doi.org/10.1073/pnas.0135058100

Gur, R. C., \& Gur, R. E. (2017). Complementarity of sex differences in brain and behavior: From laterality to multimodal neuroimaging. $J$ Neurosci Res, 95(1-2), 189-199. doi:https://doi.org/10.1002/jnr. 23830

Hampshire, A., Chamberlain, S. R., Monti, M. M., Duncan, J., \& Owen, A. M. (2010). The role of the right inferior frontal gyrus: inhibition and attentional control. Neuroimage, 50(3), 1313-1319. doi:https:// doi.org/10.1016/j.neuroimage.2009.12.109

Hampson, M., Driesen, N., Roth, J. K., Gore, J. C., \& Constable, R. T. (2010). Functional connectivity between task-positive and tasknegative brain areas and its relation to working memory performance. Magn Reson Imaging, 28(8), 1051-1057. doi:https://doi. org/10.1016/j.mri.2010.03.021

Hamson, D. K., Roes, M. M., \& Galea, L. A. (2016). Sex Hormones and Cognition: Neuroendocrine Influences on Memory and Learning. Compr Physiol, 6(3), 1295-1337. doi:https://doi.org/10.1002/cphy. c150031

Heatherton, T. F., Kozlowski, L. T., Frecker, R. C., \& Fagerstrom, K. O. (1991). The Fagerstrom Test for Nicotine Dependence: a revision of the Fagerstrom Tolerance Questionnaire. Br J Addict, 86(9), 11191127.

Hester, R., Fassbender, C., \& Garavan, H. (2004). Individual differences in error processing: a review and reanalysis of three event-related fMRI studies using the GO/NOGO task. Cereb Cortex, 14(9), 986994. doi:https://doi.org/10.1093/cercor/bhh059

Himberg, J., Hyvarinen, A., \& Esposito, F. (2004). Validating the independent components of neuroimaging time series via clustering and visualization. Neuroimage, 22(3), 1214-1222. doi:https://doi.org/10. 1016/j.neuroimage.2004.03.027

Hjelmervik, H., Hausmann, M., Osnes, B., Westerhausen, R., \& Specht, K. (2014). Resting States Are Resting Traits - An fMRI Study of Sex Differences and Menstrual Cycle Effects in Resting State 
Cognitive Control Networks. PLoS One, 9(7). doi:https://doi.org/10. 1371/journal.pone. 0103492

Hwang, K., Hallquist, M. N., \& Luna, B. (2013). The development of hub architecture in the human functional brain network. Cereb Cortex, 23(10), 2380-2393. doi:https://doi.org/10.1093/cercor/bhs227

Jafri, M. J., Pearlson, G. D., Stevens, M., \& Calhoun, V. D. (2008). A method for functional network connectivity among spatially independent resting-state components in schizophrenia. Neuroimage, 39(4), 1666-1681.

Jenkinson, M. (2003). Fast, automated, N-dimensional phaseunwrapping algorithm. Magn Reson Med, 49(1), 193-197. doi: https://doi.org/10.1002/mrm.10354

Jenkinson, M., Bannister, P., Brady, M., \& Smith, S. (2002). Improved optimization for the robust and accurate linear registration and motion correction of brain images. Neuroimage, 17(2), 825-841.

Jenkinson, M., Beckmann, C. F., Behrens, T. E., Woolrich, M. W., \& Smith, S. M. (2012). FSL. Neuroimage, 62(2), 782-790. doi: https://doi.org/10.1016/j.neuroimage.2011.09.015

Jezzard, P., \& Balaban, R. S. (1995). Correction for geometric distortion in echo planar images from B0 field variations. Magn Reson Med, 34(1), 65-73.

Joel, D., \& Fausto-Sterling, A. (2016). Beyond sex differences: new approaches for thinking about variation in brain structure and function. Philos Trans R Soc Lond B Biol Sci, 371(1688). doi:https://doi. org/10.1098/rstb.2015.0451

Jung, M., Mody, M., Saito, D. N., Tomoda, A., Okazawa, H., Wada, Y., \& Kosaka, H. (2015). Sex Differences in the Default Mode Network with Regard to Autism Spectrum Traits: A Resting State fMRI Study. PLoS One, 10(11), e0143126. doi:https://doi.org/10.1371/ journal.pone. 0143126

Juraska, J. M., \& Willing, J. (2017). Pubertal onset as a critical transition for neural development and cognition. Brain Res, 1654(Pt B), 87-94. doi:https://doi.org/10.1016/j.brainres.2016.04.012

Kaufman, J., Birmaher, B., Brent, D., Rao, U., Flynn, C., Moreci, P., . . . Ryan, N. (1997). Schedule for Affective Disorders and Schizophrenia for School-Age Children-Present and Lifetime Version (K-SADS-PL): initial reliability and validity data. $J$ Am Acad Child Adolesc Psychiatry, 36(7), 980-988.

Keulers, E. H., Goulas, A., Jolles, J., \& Stiers, P. (2012). Maturation of task-induced brain activation and long range functional connectivity in adolescence revealed by multivariate pattern classification. Neuroimage, 60(2), 1250-1265. doi:https://doi.org/10.1016/j. neuroimage.2011.12.079

Klapwijk, E. T. (2013). Increased functional connectivity with puberty in the mentalising network involved in social emotion processing. 64(2), 314-322. doi:https://doi.org/10.1016/j.yhbeh.2013.03.012

Klein, A., \& Tourville, J. (2012). 101 labeled brain images and a consistent human cortical labeling protocol. Front Neurosci, 6, 171. doi: https://doi.org/10.3389/fnins.2012.00171

Krienen, F. M., Yeo, B. T., \& Buckner, R. L. (2014). Reconfigurable taskdependent functional coupling modes cluster around a core functional architecture. Philos Trans $R$ Soc Lond B Biol Sci, 369(1653). doi:https://doi.org/10.1098/rstb.2013.0526

Kuhn, C. (2015). Emergence of sex differences in the development of substance use and abuse during adolescence. Pharmacol Ther, 153, 55-78. doi:https://doi.org/10.1016/j.pharmthera.2015.06.003

Lenroot, R. K., \& Giedd, J. N. (2010). Sex differences in the adolescent brain. Brain Cogn, 72(1), 46-55. doi:https://doi.org/10.1016/j. bandc.2009.10.008

Lenroot, R. K., Gogtay, N., Greenstein, D. K., Wells, E. M., Wallace, G. L., Clasen, L. S., . . Giedd, J. N. (2007). Sexual dimorphism of brain developmental trajectories during childhood and adolescence. Neuroimage, 36(4), 1065-1073. doi:https://doi.org/10.1016/j. neuroimage.2007.03.053

Li, C. S., Huang, C., Constable, R. T., \& Sinha, R. (2006a). Gender differences in the neural correlates of response inhibition during a stop signal task. Neuroimage, 32(4), 1918-1929. doi:https://doi.org/ 10.1016/j.neuroimage.2006.05.017

Li, C. S., Huang, C., Constable, R. T., \& Sinha, R. (2006b). Imaging response inhibition in a stop-signal task: neural correlates independent of signal monitoring and post-response processing. J Neurosci, 26(1), 186-192. doi:https://doi.org/10.1523/jneurosci.3741-05.2006

Li, C. S., Huang, C., Yan, P., Paliwal, P., Constable, R. T., \& Sinha, R. (2008). Neural correlates of post-error slowing during a stop signal task: a functional magnetic resonance imaging study. $J \operatorname{Cog} n$ Neurosci, 20(6), 1021-1029. doi:https://doi.org/10.1162/jocn.2008. 20071

Li, C. S., Zhang, S., Duann, J. R., Yan, P., Sinha, R., \& Mazure, C. M. (2009). Gender Differences in Cognitive Control: an Extended Investigation of the Stop Signal Task. Brain Imaging Behav, 3(3), 262-276. doi:https://doi.org/10.1007/s11682-009-9068-1

Long, X. Y., Zuo, X. N., Kiviniemi, V., Yang, Y., Zou, Q. H., Zhu, C. Z., . . . Zang, Y. F. (2008). Default mode network as revealed with multiple methods for resting-state functional MRI analysis. J Neurosci Methods, 171(2), 349-355. doi:https://doi.org/10.1016/j.jneumeth. 2008.03.021

Luna, B., Marek, S., Larsen, B., Tervo-Clemmens, B., \& Chahal, R. (2015). An Integrative Model of the Maturation of Cognitive Control. Annu Rev Neurosci, 38, 151-170. doi:https://doi.org/10. 1146/annurev-neuro-071714-034054

Luna, B., Padmanabhan, A., \& O'Hearn, K. (2010). What has fMRI told us about the development of cognitive control through adolescence? Brain Cogn, 72(1), 101-113. doi:https://doi.org/10.1016/j.bandc. 2009.08.005

Luna, B., \& Sweeney, J. A. (2004). The emergence of collaborative brain function: FMRI studies of the development of response inhibition. Ann N Y Acad Sci, 1021, 296-309.

Ma, S., Correa, N. M., Li, X. L., Eichele, T., Calhoun, V. D., \& Adali, T. (2011). Automatic identification of functional clusters in FMRI data using spatial dependence. IEEE Trans Biomed Eng, 58(12), 34063417. doi:https://doi.org/10.1109/tbme.2011.2167149

Mak, L. E., Minuzzi, L., MacQueen, G., Hall, G., Kennedy, S. H., \& Milev, R. (2017). The Default Mode Network in Healthy Individuals: A Systematic Review and Meta-Analysis. Brain Connect, 7(1), 25-33. doi:https://doi.org/10.1089/brain.2016.0438

Mansouri, F. A., Fehring, D. J., Gaillard, A., Jaberzadeh, S., \& Parkington, H. (2016). Sex dependency of inhibitory control functions. Biol Sex Differ, 7, 11. doi:https://doi.org/10.1186/s13293-0160065-y

Marek, S., Hwang, K., Foran, W., Hallquist, M. N., \& Luna, B. (2015). The Contribution of Network Organization and Integration to the Development of Cognitive Control. PLoS Biol, 13(12), e1002328. doi:https://doi.org/10.1371/journal.pbio.1002328

Mayer, J., \& Filstead, W. J. (1979). The Adolescent Alcohol Involvement Scale. An instrument for measuring adolescents' use and misuse of alcohol. J Stud Alcohol, 40(3), 291-300.

McCarthy, M. M. (2016). Multifaceted origins of sex differences in the brain. Philos Trans R Soc Lond B Biol Sci, 371(1688), 20150106. doi:https://doi.org/10.1098/rstb.2015.0106

Moberg, D. P., \& Hahn, L. (1991). The Adolescent Drug Involvement Scale. Journal of Adolescent Chemical Dependency, 2(1), 75-88.

Mohanty, A., Engels, A. S., Herrington, J. D., Heller, W., Ho, M. H., Banich, M. T., . . M Miller, G. A. (2007). Differential engagement of anterior cingulate cortex subdivisions for cognitive and emotional function. Psychophysiology, 44(3), 343-351. doi:https://doi.org/10. 1111/j.1469-8986.2007.00515.x

Monroe, T. B., Fillingim, R. B., Bruehl, S. P., Rogers, B. P., Dietrich, M. S., Gore, J. C., . . . Cowan, R. L. (2017). Sex Differences in Brain Regions Modulating Pain Among Older Adults: A Cross-Sectional Resting State Functional Connectivity Study. Pain Med. doi:https:// doi.org/10.1093/pm/pnx084 
Neta, M., Miezin, F. M., Nelson, S. M., Dubis, J. W., Dosenbach, N. U., Schlaggar, B. L., \& Petersen, S. E. (2015). Spatial and temporal characteristics of error-related activity in the human brain. $J$ Neurosci, 35(1), 253-266. doi:https://doi.org/10.1523/jneurosci. 1313-14.2015

Paulsen, D. J., Hallquist, M. N., Geier, C. F., \& Luna, B. (2015). Effects of incentives, age, and behavior on brain activation during inhibitory control: a longitudinal fMRI study. Dev Cogn Neurosci, 11, 105115. doi:https://doi.org/10.1016/j.den.2014.09.003

Peper, J. S., van den Heuvel, M. P., Mandl, R. C., Hulshoff Pol, H. E., \& van Honk, J. (2011). Sex steroids and connectivity in the human brain: a review of neuroimaging studies . Psychoneuroendocrinology, 36(8), 1101-1113. doi:https://doi.org/ 10.1016/j.psyneuen.2011.05.004

Petry, N. M., Kirby, K. N., \& Kranzler, H. R. (2002). Effects of gender and family history of alcohol dependence on a behavioral task of impulsivity in healthy subjects. $J$ Stud Alcohol, 63(1), 83-90.

Rabbitt, P. M. (1966). Error correction time without external error signals. Nature, 212(5060), 438.

Raichle, M. E. (2015). The brain's default mode network. Annu Rev Neurosci, 38, 433-447. doi:https://doi.org/10.1146/annurev-neuro071013-014030

Ridderinkhof, K. R., Ullsperger, M., Crone, E. A., \& Nieuwenhuis, S. (2004). The role of the medial frontal cortex in cognitive control. Science, 306(5695), 443-447. doi:https://doi.org/10.1126/science. 1100301

Roth, J. K., Johnson, M. K., Tokoglu, F., Murphy, I., \& Constable, R. T. (2014). Modulating intrinsic connectivity: adjacent subregions within supplementary motor cortex, dorsolateral prefrontal cortex, and parietal cortex connect to separate functional networks during task and also connect during rest. PLoS One, 9(3), e90672. doi:https:// doi.org/10.1371/journal.pone.0090672

Rubia, K., Smith, A. B., Taylor, E., \& Brammer, M. (2007). Linear agecorrelated functional development of right inferior fronto-striatocerebellar networks during response inhibition and anterior cingulate during error-related processes. Hum Brain Mapp, 28(11), 11631177. doi:https://doi.org/10.1002/hbm.20347

Rubia, K., Smith, A. B., Woolley, J., Nosarti, C., Heyman, I., Taylor, E., \& Brammer, M. (2006). Progressive increase of frontostriatal brain activation from childhood to adulthood during event-related tasks of cognitive control. Hum Brain Mapp, 27(12), 973-993. doi:https:// doi.org/10.1002/hbm.20237

Rubin, L. H., Yao, L., Keedy, S. K., Reilly, J. L., Bishop, J. R., Carter, C. S., . . . Sweeney, J. A. (2017). Sex differences in associations of arginine vasopressin and oxytocin with resting-state functional brain connectivity. J Neurosci Res, 95(1-2), 576-586. doi:https://doi.org/ 10.1002/jnr.23820

Ruigrok, A. N., Salimi-Khorshidi, G., Lai, M. C., Baron-Cohen, S., Lombardo, M. V., Tait, R. J., \& Suckling, J. (2014). A metaanalysis of sex differences in human brain structure. Neurosci Biobehav Rev, 39, 34-50. doi:https://doi.org/10.1016/j.neubiorev. 2013.12.004

Rutter, M., Caspi, A., \& Moffitt, T. E. (2003). Using sex differences in psychopathology to study causal mechanisms: unifying issues and research strategies. J Child Psychol Psychiatry, 44(8), 1092-1115.

Sacher, J., Neumann, J., Okon-Singer, H., Gotowiec, S., \& Villringer, A. (2013). Sexual dimorphism in the human brain: evidence from neuroimaging. Magn Reson Imaging, 31(3), 366-375. doi:https://doi. org/10.1016/j.mri.2012.06.007

Schulte, M. T., Ramo, D., \& Brown, S. A. (2009). Gender Differences in Factors Influencing Alcohol Use and Drinking Progression Among Adolescents. Clin Psychol Rev, 29(6), 535-547. doi:https://doi.org/ 10.1016/j.cpr.2009.06.003

Schulz, K. M., Molenda-Figueira, H. A., \& Sisk, C. L. (2009). Back to the future: The organizational-activational hypothesis adapted to puberty and adolescence. Horm Behav, 55(5), 597-604. doi:https:// doi.org/10.1016/j.yhbeh.2009.03.010

Schulz, K. M., \& Sisk, C. L. (2016). The organizing actions of adolescent gonadal steroid hormones on brain and behavioral development. Neurosci Biobehav Rev, 70, 148-158. doi:https://doi.org/10.1016/j. neubiorev.2016.07.036

Shackman, A. J., Salomons, T. V., Slagter, H. A., Fox, A. S., Winter, J. J., \& Davidson, R. J. (2011). The integration of negative affect, pain and cognitive control in the cingulate cortex. Nat Rev Neurosci, 12(3), 154-167. doi:https://doi.org/10.1038/nrn2994

Sharp, D. J., Bonnelle, V., De Boissezon, X., Beckmann, C. F., James, S. G., Patel, M. C., \& Mehta, M. A. (2010). Distinct frontal systems for response inhibition, attentional capture, and error processing. Proc Natl Acad Sci U S A, 107(13), 6106-6111. doi:https://doi.org/10. 1073/pnas. 1000175107

Sisk, C. L. (2017). Development: Pubertal Hormones Meet the Adolescent Brain. Curr Biol, 27(14), R706-r708. doi:https://doi. org/10.1016/j.cub.2017.05.092

Smith, D. V., Utevsky, A. V., Bland, A. R., Clement, N., Clithero, J. A., Harsch, A. E., . . . Huettel, S. A. (2014). Characterizing individual differences in functional connectivity using dual-regression and seed-based approaches. Neuroimage, 95, 1-12. doi:https://doi.org/ 10.1016/j.neuroimage.2014.03.042

Sole-Padulles, C., Castro-Fornieles, J., de la Serna, E., Calvo, R., Baeza, I., Moya, J., . . . Sugranyes, G. (2016). Intrinsic connectivity networks from childhood to late adolescence: Effects of age and sex. Dev Cogn Neurosci, 17, 35-44. doi:https://doi.org/10.1016/j.den. 2015.11.004

Sommer, I. E., Aleman, A., Bouma, A., \& Kahn, R. S. (2004). Do women really have more bilateral language representation than men? A meta-analysis of functional imaging studies. Brain, 127(Pt 8), 1845-1852. doi:https://doi.org/10.1093/brain/awh207

Spielberg, J. M., Galarce, E. M., Ladouceur, C. D., McMakin, D. L., Olino, T. M., Forbes, E. E., . . . Dahl, R. E. (2015a). Adolescent development of inhibition as a function of SES and gender: Converging evidence from behavior and fMRI. Hum Brain Mapp, 36(8), 3194-3203. doi:https://doi.org/10.1002/hbm.22838

Spielberg, J. M., Miller, G. A., Heller, W., \& Banich, M. T. (2015b). Flexible brain network reconfiguration supporting inhibitory control. Proc Natl Acad Sci U S A, 112(32), 10020-10025. doi:https:// doi.org/10.1073/pnas. 1500048112

Stevens, J. S., \& Hamann, S. (2012). Sex differences in brain activation to emotional stimuli: a meta-analysis of neuroimaging studies. Neuropsychologia, 50(7), 1578-1593. doi:https://doi.org/10.1016/j. neuropsychologia.2012.03.011

Stevens, M. C. (2016). The contributions of resting state and task-based functional connectivity studies to our understanding of adolescent brain network maturation. Neurosci Biobehav Rev, 70, 13-32. doi: https://doi.org/10.1016/j.neubiorev.2016.07.027

Stevens, M. C., Kiehl, K. A., Pearlson, G., \& Calhoun, V. D. (2007). Functional neural circuits for mental timekeeping. Hum Brain Mapp, 28(5), 394-408. doi:https://doi.org/10.1002/hbm.20285

Supekar, K., Musen, M., \& Menon, V. (2009). Development of largescale functional brain networks in children. PLoS Biol, 7(7), e1000157. doi:https://doi.org/10.1371/journal.pbio.1000157

Theresa, M. W., Mary-Lou Pardue, E., \& Pardue I. O. M. U. C. O. U. T. B. O. S. A. G. D. E. T. M. W. A. M.-L. (2001). Exploring the Biological Contributions to Human Health. Does Sex Matter? Washington (DC): National Academies Press (US); 2001.ISBN10: 0-309-07281-6.

Vink, M., Zandbelt, B. B., Gladwin, T., Hillegers, M., Hoogendam, J. M., van den Wildenberg, W. P., . . Kahn, R. S. (2014). Frontostriatal activity and connectivity increase during proactive inhibition across adolescence and early adulthood. Hum Brain Mapp, 35(9), 44154427. doi:https://doi.org/10.1002/hbm.22483 
Wechsler, D. (1999). Wechsler abbreviated scale of intelligence. The Psychological Corporation: Harcourt Brace \& Company: New York, NY.

Weis, S., Hodgetts, S., \& Hausmann, M. (2017). Sex differences and menstrual cycle effects in cognitive and sensory resting state networks. Brain Cogn. doi:https://doi.org/10.1016/j.bandc.2017.09. 003

Weston, C. S. (2012). Another major function of the anterior cingulate cortex: the representation of requirements. Neurosci Biobehav Rev, 36(1), 90-110. doi:https://doi.org/10.1016/j.neubiorev.2011.04.014

Zhang, R., Geng, X., \& Lee, T. M. C. (2017). Large-scale functional neural network correlates of response inhibition: an fMRI metaanalysis. Brain Struct Funct. doi:https://doi.org/10.1007/s00429017-1443-x
Zou, Q. H., Zhu, C. Z., Yang, Y., Zuo, X. N., Long, X. Y., Cao, Q. J., . . Zang, Y. F. (2008). An improved approach to detection of amplitude of low-frequency fluctuation (ALFF) for resting-state fMRI: Fractional ALFF. J Neurosci Methods, 172(1), 137-141. doi: https://doi.org/10.1016/j.jneumeth.2008.04.012

Zuo, X. N., Kelly, C., Di Martino, A., Mennes, M., Margulies, D. S., Bangaru, S., . . Milham, M. P. (2010). Growing together and growing apart: regional and sex differences in the lifespan developmental trajectories of functional homotopy. $J$ Neurosci, 30(45), 1503415043. doi:https://doi.org/10.1523/jneurosci.2612-10.2010

Publisher's note Springer Nature remains neutral with regard to jurisdictional claims in published maps and institutional affiliations. 